memory ... the bibliographical citations, abstracts and index headings of the corresponding documents". And so on! These are not Wellsian fancies. The technical components for such systems are available in principle and many hard-headed computer engineers are full of optimism. Yet there are still grounds for scepticism, for "software" (the intellectual aspects of subject specification greatly complicated by linguistic variability and semantic ambiguity) is far more important than "hardware".

Fortunately the author sees tho problems clearly and manages to explain to research workers how they can improve the manual organization of their own collections of documents, assumed to be of a size lying between a few hundred and ten thousand.

Essentially this guide resolves itself into a simple but effective account of the nature of indexing and the characteristics of the various indexes that are suitable for such collections. He shows how and why the traditional indexes (alphabetical subject, alphabetico-classified, hierarchically classified) have been extended (faceted classification) or replaced by the now fashionable coordinate indexes (based on thesauri), or the crudest and least controlled of all the innovations, the keyword-from-title index. Finally, the citation index, which is most effectively produced by computer, has a place under certain conditions when prepared manually for a personal collection.

The costs of production and ease in consultation are discussed in relation to the depth of indexing, the nature of access points (specific and/or generic), and the much debated questions of precision and recall in searching. Altogether this is a useful and balanced presentation of the complexities which arise in practice and can be recommended for the individual scientist, and even for students who are at the beginning of their training in documentation.

HERBERT COBLANS

\section{SHIFT OF SHEET STEEL}

The British Iron and Steel Sheet Industry since 1840 An Economic Geography. By Kenneth Warren. (Bell's Advanced Economic Geographies.) Pp. xvi +313. (Bell: London, May 1970.) 50s.

Is view of all that has been written about the history of the British iron and steel industry it is difficult to conceive just what another volume on the subject can contribute to our knowledge of that industry. Dr Warren's chief theme, it is true, is the locational aspects of one important branch of the industry, namely the sheet metal trade, and in theory at least this should provide the basis for a new slant on the industry. But to a large extent the book consists of a rather descriptive account of the decline of the Black Country in this trade and the subsequent geographical shift of the sheet industry to coastal locations.

Many factors-technical, demand, cost and politicalwere responsible for this movement and there is a wealth of interesting material relating to these matters. But the author's concern for detail and chronology make it difficult to discern which have been the most important either in a general or a specific context. There is little in the way of rigorous analysis of the costs of different locations and no mention of location theory. It is extraordinary that what is essentially a book on location can be written without even a passing acknowledgment to the theory of tho subject. It is a pity that the author allowed his geographical expertise to predominate because it seems to have resulted in the neglect of approaches to the subject which would have marked his work off from those previously published. In effect, therefore, the present volume simply fills in some of the details of the sheet branch of the iron and steel industry.

Derek H. Aldcroft

\section{Short Notices}

The Method of Science. By R. Harré. Pp. xii 123. (Wykeham: London, March 1970.) 25s.

CONDUCTED tours of the work of great scientists of the past can offer an entertaining introduction to what scientific thinking is all about, and Mr Harré proves to be an excellent courier. His chief destinations are William Gilbert on magnetism and Stephen Hales on plant life, but the journey also makes fruitful forays among the mediaevals and magicians who had been philosophizing about magnets and plants long before, and the importance of natural magic for scientists right up to the seventeenth century comes across strongly. Readers are, happily, left largely to draw their own methodological morals, although the book is aimed partly at sixth-formers and does not always resist the temptation to be obtrusively didactic.

The Naturalist in Wales. By R. M. Lockley. Pp. 231. (David and Charles: Newton Abbot, June 1970.) $55 s$.

THE naturalist packing his binoculars and vasculum in readiness for a trip to Wales would do well to squeeze a copy of this book into his rucksack as well. It will tell him what wild life he can expect to encounter in the land of song, whether his interest is birds, mammals, flowers or other forms of life. As well as chapters devoted to the distribution and natural history of each of these groups, there is a guide to places to visit, ranging from Snowdonia National Park to Borth Bog, with maps, plans and lists of wild life to be found there. Illustrations in the book include some of the commonest Welsh creatures, such as the water-ouzel and the pied flycatcher, and some of the rarest, such as the gillyflower, Matthiola incana. Pretty as the pictures are, however, the inexperienced enthusiast could not rely on this book for purposes of identification; he must arm himself with separate keys to the various species. Once thus equipped the visitor to Wales should find The Naturalist in Wales a very helpful companion.

The Encyclopaedia of the Biological Sciences. Second edition. Edited by P. Gray. Pp. 1027. (Van Nostrand Reinhold: London and New York, March 1970.) $234 s$.

WiтH entries ronging from "Abiogenesis" to "Zosterophyllophytina" in true encyclopaedic fashion, this book has deservedly found a place in biological reference libraries in the nine years since it was first published. While obviously a less satisfactory guide to recent events in rapidly changing subjects such as molecular biology (it also falls short in reporting recent discoveries in the field of primate and human evolution), it remains, nevertheless, a good source of information about structural and functional aspects of biology, and it also includes short biographies of famous biologists of the past.

The Scientific Institutions of Latin America. By Ronald Hilton. Pp. $x x+748+x x x v i$. (California Institute of International Studies: Stanford, 1970.) $\$ 12$.

THIS is a useful new guide to the organization of higher education, science and scientific information in the twenty-odd states and territories, from Mexico down to Patagonia, which are commonly grouped together as Latin America. It is the first detailed study of its kind, and is made all the more reliable because the author, with a few exceptions, made personal visits to all the institutions described. The book is arranged country by country, and institution by institution, but it is not just a list of addresses; the author describes the history and organization of the universities and research institutes and their library facilities, and at the end there is an analysis of the problems of Latin American higher education and science. 